UCRL-JC-118824

PREPRINT

\title{
A Perspective on Safeguarding and Monitoring of Excess Military Plutonium
}

W. G. Sutcliffe

$$
\begin{aligned}
& \text { PEO } \\
& \text { MAM } 16195 \\
& \text { OSTI }
\end{aligned}
$$

This paper was prepared for submittal to the

NATO Advanced Research Workshop

Obninsk, Russia

October 17, 1994

October 2, 1994

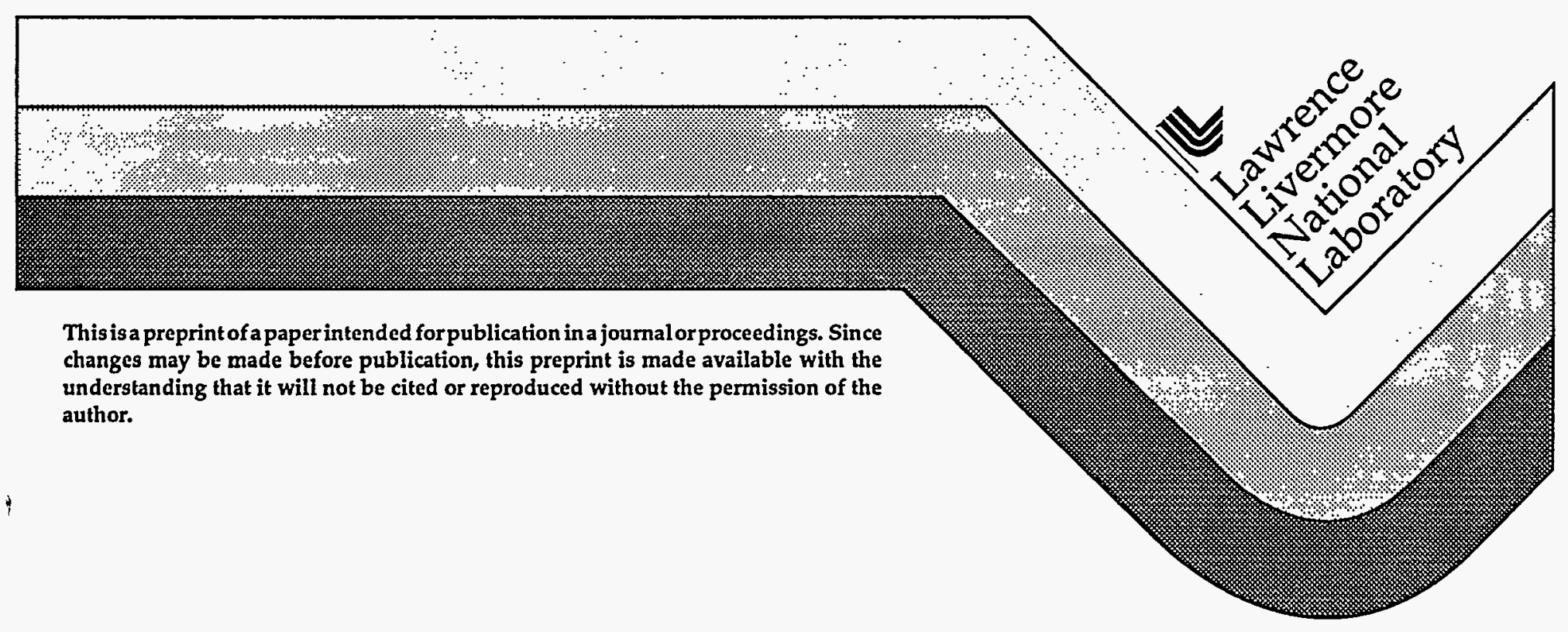




\section{DISCLAIMER}

This document was prepared as an account of work sponsored by an agency of the United States Government. Neither the United States Government nor the University of California nor any of their employees, makes any warranty, express or implied, or assumes any legal liability or responsibility for the accuracy, completeness, or usefulness of any information, apparatus, product, or process disclosed, or represents that its use would not infringe privately owned rights. Reference herein to any specific commercial product, process, or service by trade name, trademark, manufacturer, or otherwise, does not necessarily constitute or imply its endorsement, recommendation, or favoring by the United States Government or the University of California. The views and opinions of authors expressed herein do not necessarily state or reflect those of the United States Government or the University of California, and shall not be used for advertising or product endorsement purposes. 


\title{
A PERSPECTIVE ON SAFEGUARDING AND MONITORING EXCESS MILITARY PLUTONIUM
}

\author{
W. G. SUTCLIFFE \\ Center for Security and Technology Studies \\ Lawrence Livermore National Laboratory, L-019 \\ P.0.Box 808 \\ Livermore, CA 94551 USA
}

\section{Introduction}

The purpose of this paper is to provide a perspective and framework for the development of safeguarding and monitoring procedures for the various stages of disposition of excess military plutonium. The paper briefly outlines and comments on some of the issues involved in safeguarding and monitoring excess military plutonium as it progresses from weapons through dismantlement, to fabrication as reactor fuel, to use in a reactor, and finally to storage and disposal as spent fuel. "Military" refers to ownership, and includes both reactor-grade and weapon-grade plutonium. "Excess" refers to plutonium (in any form) that a government decides is no longer needed for military use and can be irrevocably removed from military stockpiles. Many of the issues and proposals presented in this paper are based on, or are similar to, those mentioned in the National Academy of Sciences (NAS) report on excess military plutonium. ${ }^{1}$

Safeguards for plutonium disposition are discussed elsewhere ${ }^{2}$ in terms of requirements established by the U.S. Department of Energy (DOE), the U.S. Nuclear Regulatory Commission (NRC), and the International Atomic Energy Agency (IAEA). Here, the discussion is less specific. The term "safeguarding" is used broadly to refer to materials control and accountancy (MC\&A), containment and surveillance (C\&S), and physical protection of nuclear materials by the state that possesses those materials. This is also referred to as material protection, control, and accountancy (MPCA). The term "safeguarding" was chosen for brevity and to distinguish MPCA considered in this paper from international or IAEA safeguards. "Monitoring" is used to refer to activities designed to assure another party (state or international organization) that the nuclear materials of the host state (the United States or Russia) are secure and not subject to unauthorized use.

Much of what is said in this paper applies not only to mixed-oxide (MOX) fuel but to any plutonium reactor fuel, and even to plutonium being disposed of directly. This 
paper deals with institutional issues associated with military plutonium as opposed to civilian plutonium, but some comments apply to both civilian and military plutonium.

\section{Arms Control, Nonproliferation, And Security Of Nuclear Materials}

In dealing with military plutonium in the United States and the Russian Federation, there is a persistent tendency to mix, and often confuse, what can be called traditional arms control with nonproliferation and with the security (against theft) of nuclear materials. Recently, traditional arms control has been concemed with START I \& II. Nonproliferation has been primarily concerned with measures aimed at preventing or discouraging a state from acquiring nuclear weapons. Historically, IAEA activities have focused on detecting the diversion of nuclear materials from nuclear power programs (in states other than the five declared nuclear weapons states). Currently, however, overt or covert theft, and trade, of nuclear materials from the former Soviet Union appears to be emerging as the new and pressing international concem.

\subsection{ARMS CONTROL}

Literally, and broadly, "arms control" refers to any activity whose aim is to control arms. For lack of a better term, "arms control" is used here to distinguish what is basically an adversarial process, in the sense that each party is concerned about the other's military intentions and capabilities. In this narrow sense, arms control agreements usually require long negotiations and costly implementation and verification measures. To be effective, verification is often quite intrusive. The primary purpose of arms control, in this sense, is to reduce the risk of (nuclear) war or, failing that, to limit the resulting devastation. A more specific objective of arms control is to equalize the military potential of the adversaries so that (nuclear) coercion is not possible. It is paradoxical that with the end of the Cold War, verification is becoming more rather than less intrusive.

Some people believe that arms control is, or should be, a major factor in dealing with excess military plutonium. Interestingly enough, in the United States there are demands in some quarters for strict measures to prevent the U.S. govemment from reusing excess plutonium in weapons. Such demands are based on various considerations, including the fear that the United States might rebuild a large or more capable stockpile of nuclear weapons and thus start a new arms race. In retrospect, it is clear that large nuclear weapons. stockpiles are not needed. ${ }^{3}$ Furthermore, without public support it is highly unlikely that any president would propose, and the Congress approve, actions that would lead to a resumption of the arms race.

Another reason for the call for strict measures against reuse in the United States is the expectation that Russia can be induced to reciprocate, and so would be hampered in restarting an arms race. To be effective in this sense, nonreuse measures would have to be coupled with a verified cutoff in the production of fissile materials for weapons, and with other measures. ${ }^{4}$ To be equitable, such an arms control regime would also have to apply to existing stockpiles of materials and weapons. Until the United States and 
Russia declare most of their plutonium to be excess and greatly reduce their stockpiles of nuclear materials and weapons (say, to the levels held by the other nuclear powers), the logic of arguments for strict nonreuse measures does not appear to be compelling. The importance of these measures is primarily to exercise methods and to set precedents for the future. Demands for reciprocity in both the United States and Russia are likely to influence the rate and mode of dealing with excess military plutonium and the . concomitant safeguarding and monitoring measures.

Finally, and most important, strict measures against reuse in weapons may be a means to convince the world that the United States and Russia are reducing the number of nuclear weapons in their stockpiles. The motivation for such an argument is to show compliance with Article VI of the Nonproliferation Treaty (NPT) ${ }^{5}$ and to bolster efforts to achieve an indefinite extension of the treaty at the 1995 review conference. To be effective (and convincing), additional measures such as a verified cutoff on the production of nuclear materials and weapons in the United States and Russia would have to be invoked. Bilateral verification of the cutoff and of nonreuse might not be sufficient. IAEA inspections, or some type of multilateral inspections, may be required. The strictness of the measures and the level of verification may be dictated by what is deemed necessary to convince the parties to the NPT to vote for an (indefinite) extension of the treaty. Although not sufficient by themselves, declarations of quantities of excess military (and civilian) plutonium, in addition to a pledge of nonreuse for weapons, would be a good start.

The form of excess plutonium, as well as the quantity, is also an issue. It is likely that some weapons components (pits) will have to be included in the materials declared as excess. The tendency to mix environmental and arms controls issues can confuse the situation. Plutonium in waste represents an énvironmental risk, rather than an arms control, nonproliferation, or security risk.

If we adopt a strict arms control perspective, then safeguarding and monitoring will be dominated by verification measures. Moreover, we are led to additional measures dealing with the production of nuclear materials, plutonium and highly enriched uranium (HEU), and to international involvement in verification.

\subsection{NONPROLIFERATION}

As mentioned above, nonproliferation (what could be called classical nonproliferation) deals with deterring a nation from acquiring nuclear weapons, nuclear weapons materials, or nuclear weapons technology. In this sense, we are concened about the intentions and capabilities of states other than the five declared nuclear weapons states. As evidenced by IAEA safeguards, considerable attention has been paid to detecting any diversion of nuclear materials from nuclear power to nuclear weapons by a host nation. Because of their large stockpiles of materials, there is little current cause for concern about diversion by the United States or Russia. Furthermore, as evidenced by their membership in and support of the Nuclear Suppliers Group, ${ }^{6}$ the United States and Russia are not likely to divert nuclear materials to other countries. However, consistency with international (IAEA) safeguards, norms, and procedures for the 
nonmilitary use or disposal of plutonium will be called for and will demonstrate support for the intemational safeguards regime.

\subsection{SECURTTY OF NUCLEAR MATERIALS}

As evidenced by recent news reports and statements from high-level German government officials, potential overt or covert theft of nuclear materials is an emerging cause for concern. What is being called for is not only the absolute protection of nuclear materials, but also measures that demonstrate such protection. Although absolute protection cannot be demonstrated, it should be possible for a country to demonstrate that protection is being provided according to rigorous standards. The most applicable standard may be the "stored weapons standard" referred to in the NAS report on the disposition of plutonium. ${ }^{7}$ This means that protection measures for excess military plutonium (and excess HEU) should go beyond current standards for commercial and research uses of plutonium. Rigorous security, such as the "stored weapons standard" (discussed in Sec. 4.2), should be applied to all separated plutonium (and HEU), excess or not, military or not.

It is not easy to demonstrate that separated plutonium is protected as well as nuclear weapons. In particular, plutonium in bulk form will have to be safeguarded during processing from weapons components to fuel. This makes protection-and the demonstration of protection-more difficult. A first step would be to make a public commitment to demonstrating that material is being protected according to the stored weapons standard. Some storage and transportation protection measures, such as the use of armed guards and safe-secure transports (SSTs), would be observable. Furthermore, the principles and many of the details of the MC\&A system could be made public. Of course, some details should remain classified to prevent subversion of the system. This area-the resolution of the tension between actual security and the demonstration of security - is an area in which additional analyses, and perhaps innovation, are required.

\section{Reactor-Grade Plutonium}

If there is no reprocessing of weapons-grade plutonium (WPu) fuel, i.e., if the once- . through cycle is adopted, then reactor-grade plutonium $(\mathrm{RPu})^{8}$ is of concem primarily as part of the context or background in which we make decisions about the disposition of WPu. ${ }^{9} \mathrm{RPu}$ in MOX spent fuel is only slightly different from RPu in light water reactor (LWR) spent fuel. ${ }^{10}$ If reprocessing is involved, we must consider (or reconsider) safeguarding and monitoring $\mathrm{RPu} .11$ Although we have called for the application of the stored weapons standard to all separated plutonium, including RPu, that does not mean that all separated plutonium is the same.

First, a caveat concerning Pu-238. Because of its high heat output (about $560 \mathrm{~W} / \mathrm{kg}$, as against $1.9 \mathrm{~W} / \mathrm{kg}$ for Pu-23912), Pu-238 cannot readily be made into a weapon; thus the level of protection For Pu-238 need not be as rigorous as that for other plutonium, and is based on the risk to humans and the environment. Accordingly, plutonium containing more than $80 \% \mathrm{Pu}-238$ is exempt from international safeguards. ${ }^{13}$ 
The fact that a weapon can be made from RPu has been amply discussed elsewhere. ${ }^{14}$ (It is interesting to note, however, that the 1962 U.S. nuclear test often cited as proof of this fact was not a proliferation experiment. ${ }^{15}$ ) The attractiveness of RPu depends on the circumstances of the potential proliferants and on the use they intend for nuclear weapons. Circumstances can vary from a state with a stockpile of RPu that wants to quickly develop a nuclear weapons capability, to a terrorist group that wants to present a high-visibility threat.

$\mathrm{RPu}$ is less attractive than WPu because of the uncertainty in yield, the radiation caused by the spontaneous fission neutrons from Pu-240, the heat resulting from the decay of $\mathrm{Pu}-238$, and the gamma radiation from the Am-241 that results from the decay of $\mathrm{Pu}-241$. Each kilogram of $\mathrm{Pu}-240$ produces about $10^{6}$ neutrons per second, as against only about 30 neutrons per second produced by each kilogram of Pu-239. ${ }^{16}$ This results in a higher preinitiation probability, which leads to an uncertainty in yield. However, a significant "fizzle" yield is always possible. ${ }^{17}$ Depending on the intended use, this yield uncertainty may or may not present a problem.

The design of a weapon is further complicated by the heat output of RPu. In particular, in a system insulated with high explosive, a rise in temperature could cause swelling due to a phase change in the plutonium. This change in geometry could render the weapon less effective or unusable. However, it is well known that the phase (and hence the density) of plutonium can be stabilized by adding small amounts (about 1\%) of gallium. There are also potential problems with the high explosive. The heat could melt or even ignite it. Various experts have advanced ideas for dealing with the heat, but these further complicate the design. The heat generated by RPu is 10 to $15 \mathrm{~W} / \mathrm{kg}$, as against about $2.4 \mathrm{~W} / \mathrm{kg}$ for $\mathrm{WPu}{ }^{18}$ This difference might not preclude the design of a workable weapon using $R P u$, but it is a disincentive:

In fabricating a weapon from $\mathrm{RPu}$, the potential human radiation exposure might be considered. The neutron exposure would scale with the greater number of neutrons in $\mathrm{RPu}-$ about a factor of three more, depending on the amount of Pu-240. Depending on the geometry, the gamma dose would be increased by about an order of magnitude. Radiation exposure could be reduced to manageable levels by shielding, so that radiation would complicate, but not preclude, the fabrication of a weapon from $\mathrm{RPu}$.

As with fabrication, there could be concerns about exposure of (military) personnel handling weapons made from $\mathrm{RPu}$. The gamma radiation is primarily due to the $60-\mathrm{keV}$ photons from Am-241. In a weapon (a metal sphere), most of these photons would be shielded by the plutonium itself. In addition to this self-shielding, the radiation emanating from the plutonium surface would be shielded by any additional layer of heavy material, such as a tamper or case. The neutrons, on the other hand, are not effectively self-shielded. As in the case of fabrication, the neutron radiation is increased by about a factor of three. This level of radiation would probably only be a concern where several weapons were stored in a small space, such as in a submarine.

Finally, it is known that weapons using WPu can be made and stored for more than a decade. No such certainty exists for weapons that might be made from RPu. The combined effects, over time, of heat and radiation in a varying environment, on the various materials in a nuclear weapon are unknown. This might not be a source of 
concern for a terrorist, but it might be a consideration for a state planning to acquire a nuclear weapons stockpile. Unless there were no alternative, or unless urgency or secrecy dictated the use of RPu, a state would likely produce WPu. Thus far it appears that no nation has chosen to develop nuclear weapons from $\mathrm{RPu}$.

Currently, the principal cause for concern, with regard to $R P u$, is a potential terrorist. Although fabricating a workable nuclear weapon is a nontrivial endeavor, a terrorist group (including several well-equipped individuals with skills in chemical processing, high explosives, fusing, etc.) might succeed in building one, and because the consequences could be horrible, we must protect against this possibility. For this reason, separated RPu should receive the same level of protection as separated WPu. It is important to recognize that because of design, fabrication, and handling considerations, HEU is a more attractive target and must be likewise protected.

\section{Objectives For Safeguarding And Monitoring}

Having discussed possible problems (or confusions), we now turn to a statement of objectives for the safeguarding and monitoring of excess military plutonium. It is most important that a clear set of objectives be evident when developing and implementing measures and procedures.

Objectives for safeguarding and monitoring should support the overall goals and objectives for disposition. The National Academy of Sciences report ${ }^{19}$ states: "The primary goal in choosing options for management and disposition of excess nuclear weapons and fissile materials should be to minimize the risks to national and international security posed by the existence of this material. This security goal can be divided into three main objectives:

1. to minimize the risk that weapons or fissile materials could be obtained by unauthorized parties;

2. to minimize the risk that weapons or fissile materials could be reintroduced into the arsenals from which they came, halting or reversing the arms reduction process: and

3. to strengthen the national and international control mechanisms and incentives designed to ensure continued arms reductions and prevent the spread of nuclear weapons."

It follows from these objectives that security, rather than economics or energy considerations, will be the primary criterion in choosing disposition options and technologies. ${ }^{20}$ That is, options and technologies for disposition should be chosen so that safeguarding and monitoring procedures can be effectively implemented and so that excess materials are processed "sooner rather than later."

In particular, the objectives for safeguarding (materials control and accountancy, containment and surveillance, and the physical protection) and monitoring (bilateral or international) should include the following:

1. preventing theft and unauthorized use;

2. demonstrating that the control, accounting, and security for separated excess

plutonium are comparable to those for nuclear weapons; and 
3. detecting any reuse for weapons by the host country.

These objectives are very similar to the purposes stated in the U.S. DOE Notice of Intent (NOI) to Prepare a Programmatic Environmental Impact Statement (PEIS) for Storage and Disposition of Fissile Nuclear Materials. ${ }^{21}$ Although the NOI takes into account support for national and international arms control mechanisms, it could be improved by broadening the scope to explicitly include linkage between the U.S and Russian disposition programs. That is, in making key decisions for the management and disposition of U.S. excess fissile materials, potential beneficial impacts on the Russian program should be considered. ${ }^{22}$ In particular, options and technologies that enhance Russian safeguarding ${ }^{23}$ and monitoring, by whatever synergy (joint or cooperative R\&D, etc.), should be favored.

The first objective, preventing theft and unauthorized use, is clear and relies primarily on physical protection provided by the host nation. MC\&A and C\&S also play a significant role in deterring attempts to obtain nuclear materials illicitly. The second objective is more difficult to achieve but is critically important. (It is no longer sufficient for custodians of nuclear material to just say "trust us.") Achievement of this objective can also support achievement of the first objective by focusing attention on crucial activities and issues. The primary purpose of the third objective is to support the NPT and the international safeguards regime. The reuse question could gain significance when several nations join a materials control regime.

The above objectives should be kept in mind when choosing options and technologies and when developing safeguarding and monitoring procedures for the various stages through which plutonium passes in the disposition process.

Figure 1 shows the disposition stages, proposed protection standards, and areas for possible monitoring and declaratory regimles.

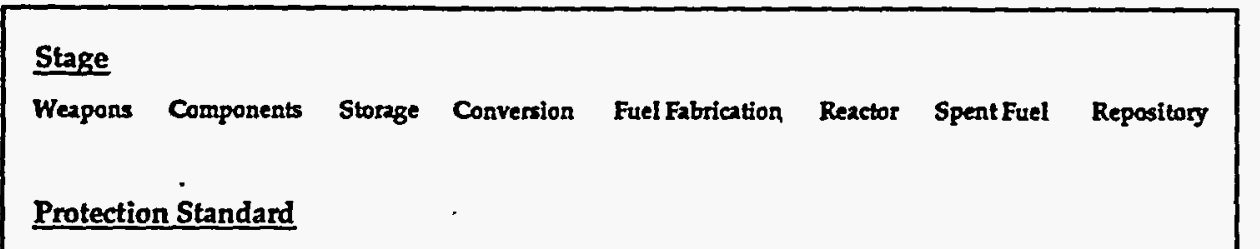

Stored Weapons Standard L I Spent Ful Standard

Monitoring Regime

National

Declarations

$\square$ Subsequent

Initial

Figure 1. Disposition stages, proposed protection standards, and areas for passible monitoring and declaratory regimes. 


\subsection{STAGES}

The first line in Fig. 1, labeled "Stage," refers to the sequence of states and processes through which the plutonium passes as it progresses from the stockpile to the repository. This figure does not show the plutonium in bulk, metal, scrap, waste, etc. This is a real complication, because some of these materials must be carefully protected, and some may be more of an environmental hazard than a security concern. Some of these forms might be fabricated into MOX; others might be disposed of directly. The figure also does not show reprocessing, which may or may not be part of the path. For simplicity, transportation, which will occur between many stages, is not shown explicitly. "Storage" may also. occur at many stages, but it is only indicated after the weapons are dismantled into components. This stage is important because the United States is supporting the Russian construction of a storage facility that will accommodate components, and this may be a key stage for monitoring and declarations. "Conversion" refers to the recovery of plutonium from disassembled weapons components or production residues and the conversion of metal into oxide. It is pointed out as a stage where international monitoring might first be applicable. The remaining stages are self-explanatory. The open boxes indicate areas of uncertainty.

\subsection{PROTECTION STANDARDS}

The "stored weapons standard" is not precisely defined, but it is sufficiently descriptive to be useful. Because the time and difficulty involved in processing oxide to metal and fabricating a weapon are not prohibitive, it is proposed that a stored weapons standard be applied in each stage of the disposition process until the fuel is loaded into the reactor. In a detailed and graded approach, U.S. DOE Order 5633.31 defines different attractiveness levels and corresponding "safeguards" categories for nuclear weapons, components and materials. ${ }^{24}$ Such as approach could be adopted for all separated weapons-usable fissile materials.

Obtaining separated plutonium or fresh MOX fuel is distinctly different from possessing a nuclear weapon or component. It is by no means a foregone conclusion

1 that a terrorist group could successfully process and fabricate plutonium or fuel into a workable nuclear explosive; but they might do so, and we must therefore protect against that risk. Extension of a stored weapons standard to all separated plutonium and HEU and fresh plutonium or HEU fuel would strengthen international confidence in the security of nuclear materials.

The NAS committee, realizing that there is a wide variation in the nature and age of spent fuel around the world, nevertheless felt that it was useful to use the term "spent fuel standard" in discussing disposition criteria. This "standard" does not necessarily imply that the spent fuel is self-protecting, nor that it is suitable for disposal in a geologic repository. Using the term "spent fuel standard" recognizes that there are several hundred tonnes of plutonium in spent fuel around the world ${ }^{25}$ and that it is not worthwhile to take exceptional measures to make spent fuel from the 200 or so tonnes of WPu less available or less attractive for weapons than RPu from civilian spent fuel. 
Similarly, plutonium that is immobilized and disposed of directly should be no more available or attractive for weapons than RPu in spent fuel. This last issue, which is not of direct relevance for this paper, is more problematic. First, a spent fuel standard is not precisely defined, and second, a security equivalence relation would have to be developed taking into account the characteristics (size, weight, composition, etc.) of the plutonium-bearing objects (e.g., glass logs). This equivalence relation could vary depending on the threat scenarios considered.

Although much less attractive than weapons, components, or separated material, spent fuel is a potential source of plutonium or HEU. The principal factor inhibiting the separation of plutonium from spent fuel is the radioactivity. It is generally believed that irradiated spent fuel is so radioactive (self-protecting) that it can be moved and processed only with specialized equipment and facilities. However, it is conceivable that a small, possibly subnational, group acting in secret with no concern for the environment (other than for the reduction of tell-tale signatures) and willing to incur substantial but not lethal radiation doses, could obtain plutonium by stealing and processing irradiated spent fuel that had cooled for 15 to 20 years. ${ }^{26}$ It should be noted that spent fuel from research or naval reactors containing HEU might be a more attractive target than spent fuel containing plutonium. As with fabricating a weapon, it is by no means a foregone conclusion that a terrorist group could successfully steal and process spent fuel to obtain plutonium; but they might so do, and we must therefore also protect against this risk. Appropriate levels of protection could be defined, given the physical characteristics of the spent fuel (makeup, exposure history, age, size, weight, fissile material content, etc.).

According to the U.S. Nuclear Regulatory Commission (and the IAEA), spent fuel can be considered to be "self protecting" if the unshielded dose rate in air one meter from a spent fuel assembly is $100 \mathrm{rad} / \mathrm{hr}$ ( $1 \mathrm{~Gy} / \mathrm{hr}$ ) or more. The NAS report suggests that this "standard" should be reexamined. Specification of this standard requires more detail, such as the orientation of the fuel assembly. The adequacy of this standard depends on a number of factors. Of course, on-site physical protection measures, including guards, fences, and alarms, are a principal line of defense and deterrent. The more robust the physical protection measures, the less reliance need be placed on the spent-fuel radiation barrier and, conversely, the greater the radiation barrier the less reliance need be placed on the physical protection measures. Unfortunately, the physical protection measures must be based on the least radicactive fuel. The precise relation between radiation and physical protection barriers must be determined in the context of credible threats or scenarios. One hundred rad/hr is not adequate in all cases.

The adequacy of local and regional law enforcement becomes a key issue when there is no radiation barrier (as in the case of separated materials or fresh fuel), when the radiation barrier is inadequate (as in the case of 15- to 20-year-old fuel), and if the physical protection measures are overcome. The existence and ability of police or military forces to prevent the theft of plutonium or HEU or to recover spent fuel before the plutonium could be separated may be a key consideration in determining the level of physical protection required. Assessing the adequacy of law enforcement may be problematic. One can count the number of officers or troops and vehicles and take their . 
location into account, but a more operational assessment would also be desirable. Because banks everywhere protect a universally common asset (money or gold), one possibility might be to look at the relative risk at various localities as reflected by bank insurance premiums. The analogy is by no means perfect, but it might help in evaluating the differences in safeguarding measures appropriate in Russia, Europe, Japan, and the United States.

\subsection{MONITORING-REGIMES}

It is unlikely that nuclear weapons will be monitored soon, other than by the states that possess them (with the possible exception of states of the former Soviet Union). But monitoring, at least portal-perimeter monitoring, of weapon dismantlement facilities is called for in the NAS report. Also, bilateral monitoring of stored components declared excess is likely to be a condition for U.S. support of the construction of the proposed Russian storage facility. Reciprocity will probably dictate bilateral monitoring of excess stored components in the United States. If the monitoring were limited to portalperimeter monitoring and chain-of-custody measures (tags and seals), international monitoring starting with stored components (in containers) could be possible. Depending on the processes used and the intrusiveness deemed acceptable, some international monitoring of conversion might be possible. In any case, it would be natural to introduce international monitoring at the fuel fabrication stage, as the IAEA monitors civilian plutonium fuel fabrication. From this stage through disposal, monitoring can be combined with some aspects of safeguarding. Application of IAEA safeguards could serve as a vehicle to accomplish the aim of monitoring (to assure other states or international organizations that the nuclear materials of the host state are secure and not subject to unauthorized use). It is important to keep in mind the objective being sought when developing monitoring procedures. Intrusive measures, such as the identification of nuclear weapons components, may not be necessary. Cooperative nonproliferation and security measures should not be confused with adversarial arms control measures.

\subsection{DECLARATIONS}

Although declarations are usually coupled to monitoring or verification, they can be considered to be an effective first step towards a more comprehensive regime that includes monitoring or verification ${ }^{27}$ In addition to being the basis for monitoring the disposition of excess weapons materials, declarations can facilitate cooperation in other areas, such as nuclear waste management, environmental restoration, and conversion (to peaceful use) of nuclear weapons facilities.

A number of declarations have already been made. The United States has shut down its plutonium production reactors and has declared its intention not to produce any more fissile material for weapons; Russia has declared its intention to stop production by the year $2000 .{ }^{28}$ On June 23, 1994 the U.S. and Russian governments (in the persons of Gore and Chernomyrdin) signed an agreement embracing these intentions and going 
beyond them to state that henceforth plutonium from production reactors would not be used for weapons and that the United States and Russia would seek alternative sources of electricity and heat so that the Russian reactors could be shut down as soon as practicable. The United States has also declared the total amount of plutonium produced (102 tonnes, including 13 tonnes of RPu). ${ }^{29}$

The United States and Russia may soon declare initial amounts of excess plutonium and HEU. (Russia has in fact declared 500 tonnes of HEU to be excess by agreeing to sell that much for incorporation into LEU fuel.) In order to facilitate monitoring, the amounts of excess materials fabricated into fuel, utilized in reactors, and finally either recycled or disposed of should also be specified. As plans and agreements for the number of nuclear weapons in future stockpiles are reached (e.g., START II), the approximate total amounts of excess materials could be declared. At the Clinton-Yeltsin summit in Washington in September 1994, it was agreed that the United States and the Russian Federation would exchange information on nuclear weapons and materials. ${ }^{30}$ Although these declarations are to be confidential, they could set a precedent and could form the basis for declarations by the five nuclear weapons states and eventually by all states.

To establish confidence around the world and to support the type of declaratory regime called for in the NAS report, declarations would have to be followed by monitoring, possibly by bilateral monitoring at first. In the plutonium disposition programs, the United States and Russia have the opportunity to develop the groundwork (standards, precedents, etc.) for an expanding nuclear materials regime. As stockpiles of weapons and materials are reduced, the three other declared nuclear weapons states could be invited (or perhaps induced by world opinion) to participate. The ultimate purpose would be to create a worddwide regime that was focused on the accounting and protection of all weapons-capable materials.

\section{Summary}

The disposition of excess military plutonium focuses attention on safeguarding and monitoring and introduces a number of new issues. These have been discussed and a number of observations and proposals have been put forward. These include:

- It follows from NAS objectives for the management and disposition of excess materials that security, rather than economics or energy considerations, will be the primary criterion in choosing options and technologies.

- The objectives of arms control, nonproliferation, and security of nuclear materials are not identical, and they should not be confused when developing safeguarding and monitoring measures.

- Objectives for safeguarding and monitoring should be clear and should include the following:

1. The prevention of theft and unauthorized use.

2. The demonstration that the control, accounting, and security for separated excess plutonium are comparable to those for nuclear weapons.

3. The detection of any reuse for weapons by the host country. 
- The choice of disposition options and technologies will depend in large part on the efficacy of safeguarding and monitoring measures.

- All separated plutonium, military and civilian (WPu and $R P u$ ), should be protected according to a "stored weapons standard."

- Spent fuel needs an appropriate level of physical protection, which depends on the age of the oldest fuel and on local law enforcement capabilities.

- Cooperative monitoring (for nonproliferation and security), as opposed to adversarial verification, may be extended to nuclear weapons components and materials.

- International monitoring will probably start with fuel fabrication or earlier.

- The purposes of international safeguards for excess military plutonium include demonstrating stockpile reductions in accordance with Article VI of the NPT and supporting the international safeguards regime.

- More study is needed on how to demonstrate the security of plutonium without compromising its protection.

- Declarations of amounts of excess nuclear materials should begin promptly and should be deliberately expanded to include all nuclear materials.

\section{Acknowledgments}

This work was performed under the auspices of the U.S. Department of Energy by Lawrence Livermore National Laboratory under contract No. W-7405-ENG-48. The author thanks those colleagues who reviewed this paper, and especially thanks D.F. Bunch of Management Strategies, Inc. and P. L. Chrzanowski and C. E. Walter of Lawrence Livermore National Laboratory, who provided many detailed comments and suggestions. The author also gratefully acknowledges the editorial assistance of $P$. W. Murphy of the Technical Information Department of Lawrence Livermore National Laboratory. 
Reference

1. Committee on International Security and Arms Control, National Academy of Sciences, Management and Disposition of Excess Weapons Plutonium, National Academy Press, Washington, DC (1994).

2. L. Lee Thomas and R. Scott Strait, Safeguards and Security Issues-Weapons . Plutonium in Light Water Reactors, Lawrence Livermore National Laboratory, Livermore, CA, Plutonium Disposition Study Report LPDS-027 (August 1994). D. Kers and J. Blasy, Plutonium Disposition Study-Safeguards and Security Briefing for Advanced/Evolutionary and Existing Reactor Options, Lawrence Livermore National Laboratory, Livermore, CA, Plutonium Disposition Study Report LPDS-035 (July 1994).

3. Modern systems, such as SLBMs, provide the necessary elements of deterrence, i.e. survivable, deliverable, and reliable weapons.

4. On September 26, 1994, in a speech at the United Nations, President Yeltsin proposed that the five nuclear weapons states agree to a fissile material production cutoff.

5. Treaty on the Non-Proliferation of Nuclear Weapons, Arms Control and Disarmament Agreements-Texts and Histories of the Negotiations, U.S. Arms Control and Disarmament Agency, 1990 Edition.

6. Carlton E. Thorne, The Nuclear Suppliers Group: A Major Success Story Gone Unnoticed, Director's Series on Proliferation, edited by Kathleen C. Bailey, Lawrence Livermore National Laboratory, Livermore, CA, UCRL-LR-114070-3 (1994).

7. Committee on International Security and Arms Control, National Academy of Sciences, Management and Disposition of Excess Weapons Plutonium, National Academy Press, Washington, DC (1994), p. 31.

8. It is important to note that by $\mathrm{RPu}$ we are referring to plutonium derived from light water reactor (or heavy water reactor) spent fuel. Plutonium from other reactors, such as a gas-cooled reactor or an advanced liquid metal reactor (ALMR), presents different problems to the potential proliferant. In particular, the ALMR material has a higher radiation and heat output and is always mixed with other transuranic elements, making it unsuitable for use in weapons.

9. Both the United States and the Russian Federation have stocks of RPu. However, the United States stocks are primarily in the form of unseparated spent fuel, while the Russian Federation stocks include approximately 30 tonnes of separated RPu at Mayak.

10. C. E. Walter, Potential for Use of All-MOX Fuel in Existing and Evolutionary, and Advanced LWRs in the United States, NATO Advanced Research Workshop: "Mixed Oxide Fuel (MOX) Exploitation and Destruction in Power Reactors," Obninsk, Russia, October 17, 1994. 
11. E. A. Hackle, J. L. Richter, and M. F. Mullen, Reassessment of Safeguards Parameters, Los Alamos National Laboratory, Los Alamos, NM, LA-UR-94 2123 Preprint (1994).

12. OECD, Plutonium Fuel: An Assessment, OECD, Paris, p. 24 (1989).

13. Intemational Atomic Energy Agency, Vienna, INFCIRC/153, Paragraph 36 (1971).

14. J. Carson Mark, Explosive Properties of Reactor-Grade Plutonium, Science \& Global Security, 1992, Vol. 3, pp. 1-13.

Egbert Kankeleit, Christian Küppers, and Ulrich Imkeller, Bericht zur Waffentauglichkeit von Reaktorplutonitim, IANUS-1/1989, Institut für Kernphysik, Technische Hochschule Darmstadt [Lawrence Livermore National Laboratory, Livermore, CA, Translation No. 04191 (1/22/93), Report on The Usability of Reactor Plutonium in Weapons].

15. "This test was conducted to obtain nuclear design information concerning the feasibility of using reactor-grade plutonium as the nuclear explosive material." DOE Openness Press Conference, Fact Sheets, June 27, 1994.

16. OECD, Plutonium Fuel: An Assessment, OECD, Paris, p. 24 (1989).

17. Committee on International Security and Arms Control, National Academy of Sciences, Management and Disposition of Excess Weapons.Plutonium, National Academy Press, Washington, DC (1994), p. 33.

18. For isotopic composition of WPu, see Carl E. Walter, Ed., Recovery of Weapons Plutonium as Feed Material for Reactor Fuel, Lawrence Livermore National Laboratory, Livermore, CA, UCRL-ID-117010 (March 16, 1994). For isotopic composition of RPu see David Albright, Frans Berkhout, and William Walker, World Inventory of Plutonium and Highly Eririched Uranium, 1992, SIPRI, Oxford University Press (1993). Thermal output for plutonium isotopes and Am241 are given in Table 2 of OECD, Plutonium Fuel: An Assessment, OECD, Paris (1989), p. 24.

19. Committee on International Security and Arms Control, National Academy of Sciences, Management and Disposition of Excess Weapons Plutonium, National Academy Press, Washington, DC (1994), p. 61.

20. Economic and energy resource factors appear to be more important in the Russian Federation than in the United States. More analysis of real and missed opportumity costs in the Russian Federation are called for in order to evaluate the costs and benefits.

21. U.S. Department of Energy, Notice of Intent to Prepare a Programmatic Environmental Impact Statement for Storage and Disposition of Weapon-Usable Fissile Materials, Federal Register, vol. 59, no. 118, p. 31985 (June 2, 1994).

22. Committee on International Security and Arms Control, National Academy of Sciences, Management and Disposition of Excess Weapons Plutonium, National Academy Press, Washington, DC (1994), p. 62.

23. Oleg Bukharin, "U.S.-Russian Cooperation in the Area of Nuclear Safeguards," The Nonproliferation Review, vol. 2, No. 1, p. 30 (Fall 1994). 
24. These levels and categories are displayed in Committee on International Security and Arms Control, National Academy of Sciences, Management and Disposition of Excess Weapons Plutonium, National Academy Press, Washington, DC (1994), Table 3-2.

25. David Albright, Frans Berkhout, and William Walker, World Inventory of Plutonium and Highly Enriched Uranium, 1992, SIPRI, Oxford University Press (1993), Tables 5.2 and 5.3.

26. W. R. Lloyd, M. K. Sheaffer, and W. G. Sutcliffe, Dose Rate Estimates from Irradiated Light-Water-Reactor Fuel Assemblies in Air, Lawrence Livermore National Laboratory, Livermore, CA, UCRL-ID-115199 (1994).

27. W. G. Sutcliffe, A "New" Regime for Nuclear Weapons and Materials, Lawrence Livermore National Laboratory, Livermore, CA, UCRL-JC-116213 Preprint, Lawrence Livermore National Laboratory (1994).

28. The United States stopped production of HEU for weapons in 1964, the Russian Federation in 1989.

29. DOE Openness Press Conference, Fact Sheets, December 7, 1993.

30. They agreed to "exchange detailed information at the Next meeting of the GoreChernomyrdin Commission on aggregate stockpiles of nuclear warheads, on stocks of fissile materials and on their safety and security. The sides will develop

- a process for exchanging this information on a regúlar basis." The White House, Office of the Press Secretary, September 28, 1994. 




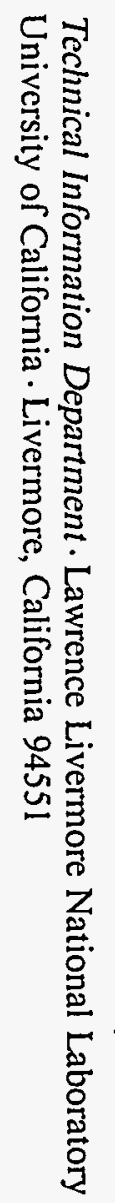

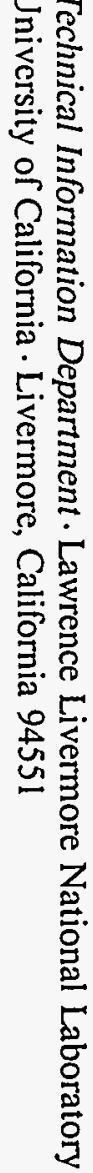

